\title{
Assessment of biocompatibility of ureasil- polyether hybrid membranes for future use in implantodontology
}

João Augusto Oshiro Junior, Gabriel Riquieri Mortari, Rubens Moreno de Freitas, Elcio Marcantonio-Junior, Leandro Lopes, Luis Carlos Spolidorio, Rosemary Adriana Marcantonio \& Leila Aparecida Chiavacci

To cite this article: João Augusto Oshiro Junior, Gabriel Riquieri Mortari, Rubens Moreno de Freitas, Elcio Marcantonio-Junior, Leandro Lopes, Luis Carlos Spolidorio, Rosemary Adriana Marcantonio \& Leila Aparecida Chiavacci (2016) Assessment of biocompatibility of ureasilpolyether hybrid membranes for future use in implantodontology, International Journal of Polymeric Materials and Polymeric Biomaterials, 65:13, 647-652, DOI: 10.1080/00914037.2016.1157796

To link to this article: https://doi.org/10.1080/00914037.2016.1157796

曲 Published online: 02 May 2016.

Submit your article to this journal $₫$

Џ Article views: 93

View Crossmark data $\subset$

Citing articles: 3 View citing articles $\widetilde{ }$ 


\title{
Assessment of biocompatibility of ureasil-polyether hybrid membranes for future use in implantodontology
}

\author{
João Augusto Oshiro Junior ${ }^{\mathrm{a}}$, Gabriel Riquieri Mortari ${ }^{\mathrm{b}}$, Rubens Moreno de Freitas ${ }^{\mathrm{b}}$, Elcio Marcantonio-Junior ${ }^{\mathrm{b}}$, Leandro \\ Lopesc, Luis Carlos Spolidorio $^{b}$, Rosemary Adriana Marcantonio ${ }^{b}$ and Leila Aparecida Chiavacci ${ }^{a}$

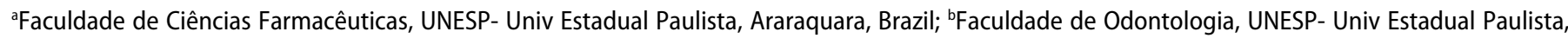 \\ Araraquara, Brazil; Instituto de Química, UNESP-Univ Estadual Paulista, Araraquara, Brazil
}

\begin{abstract}
The biocompatibility of ureasil-polyether hybrid materials has been tested for future application as membrane barrier. The authors evaluated ureasil-polyether hybrids membranes with different swollen behaviors: more swellable ureasil-poliethylene oxide (ureasil-PEO) of molecular wheigth $1900 \mathrm{~g} \cdot \mathrm{mol}^{-1}$ and less swellable ureasil-polypropilene oxide (ureasil-PPO) of molecular wheigth $400 \mathrm{~g} \cdot \mathrm{mol}^{-1}$. The swollen behavior was monitored by SAXS measurements and in vivo assays using Rattus Norvegicus were used to study their biocompatibility. The results obtained were compared with the same treatment made with collagen commercial membranes. It was observed that for commercial collagen membranes, inflammatory levels declined after seven days. The ureasil-PEO induced a greater influx of inflammatory cells during 30 days which could be associated with the higher degree of swelling. The ureasil-PPO membranes exhibited a smaller level of inflammatory cells and are good candidates for application as biomaterial, considering their low cost, ability to deliver active molecules, and biocompatibility.
\end{abstract}

\section{GRAPHICAL ABSTRACT}

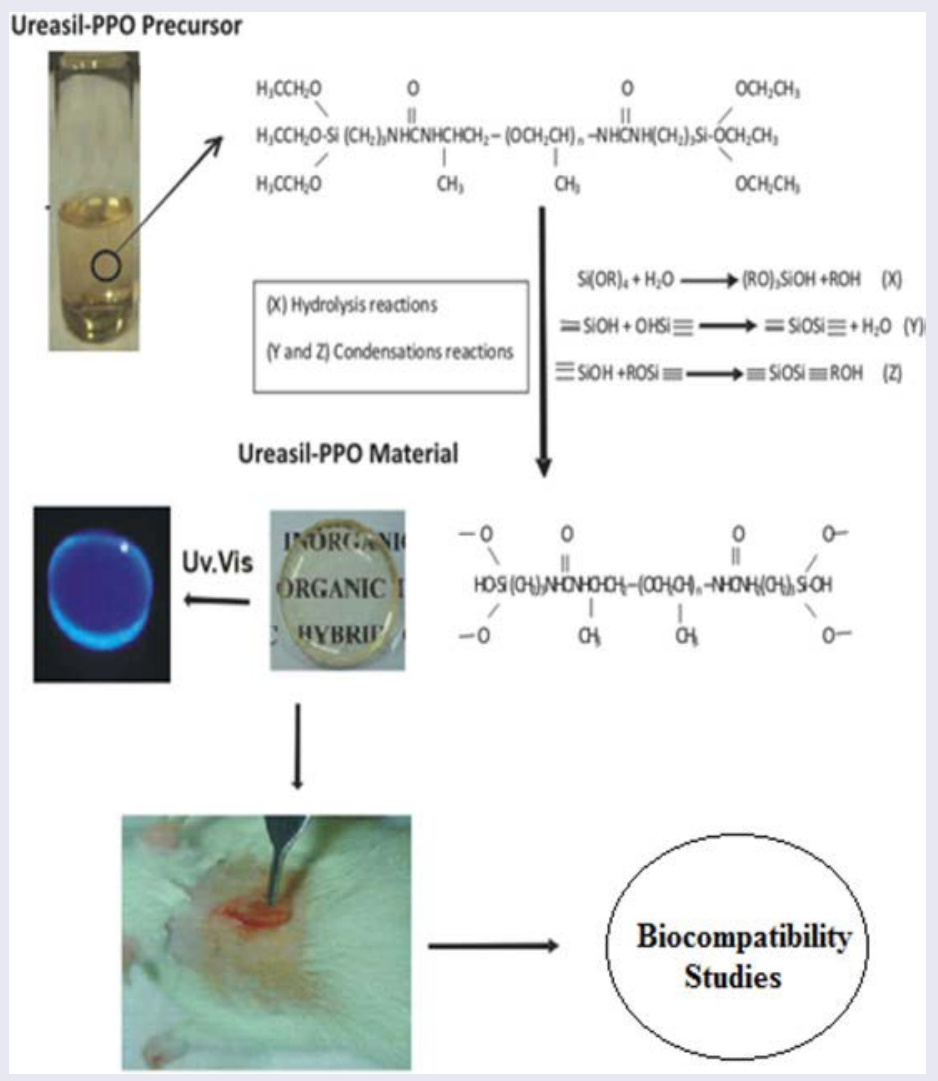

ARTICLE HISTORY

Received 27 October 2015

Accepted 21 February 2016

\section{KEYWORDS}

Biocompatibility;

membranes; ureasil-

polyether hybrid materials

CONTACT Leila Aparecida Chiavacci leila@fcfar.unesp.br Faculdade de Ciências Farmacêuticas, UNESP, Araraquara-Jaú Interstate Highway, Km 1, 14801-902 Araraquara, SP, Brazil.

Color versions of one or more of the figures in the article can be found online at www.tandfonline.com/gpom. 


\section{Introduction}

One of the limiting factors in Implantology is the quality and quantity of bone tissue available for dental implants. When the bone tissue is not adequate the surgeon should necessarily use a technique for bone grafting in order to recover the lost tissue and to enable the rehabilitation of the implant area [1,2].

For many years, the autologous bone graft was the main alternative and in this case the tissue to be grafted is removed from the patient himself. This process is known as the "gold standard" for the correction of bone defects and has become the most predictable method [3,4]. However, in many cases there is not enough amount of intraoral autologous bone tissue available for filling or even for correction of these defects [1-5]. Other unfavorable factor inherent to autologous bone graft is the morbidity of the donor site, which is characterized by the presence of pain, vascular injury during surgery, post operative resorption, irregular contours of the angular grafts, requirement of two surgical sites (receiver and donor) and also the possibility of infections and paresthesia [6-9].

To minimize such problems synthetic biomaterials have been developed with the function of replacing bone tissue [10]. However, these biomaterials usually not present osteogenic and osteoinductive capacity and thus, the amount of bone tissue formed is not enough to perform the implant process. In this context, researches have been dedicated to the development of new materials that can, due to the inherent or acquired (through structural changes) features, interact with biological targets optimizing the bone regeneration. The use of nanostructured polymeric organic-inorganic hybrid materials in the development of new alternatives to implantodonty is promising since they can be employed in different areas such as medicine, agriculture, materials science, chemistry and pharmacy offering numerous advantages. In particular a class of organic-inorganic hybrid materials called ureasilpolyether, due to the interpenetration in nanoscale of inorganic and organic phases, is able to gather unique properties in a matrix, such as high thermal and mechanical resistance, flexibility, and control of drug release [11-13]. Another interesting property of these hybrids is the luminescence (see Graphical Abstract) that can facilitate the image diagnosis.

Recently, these ureasil-polyether materials of different molecular weights were studied, aiming to assess these materials as drug delivery systems $[11,14]$. The results showed that the chemical nature and the molecular weight of the precursors affect the final properties of the matrices. Beyond that, these factors could allow the incorporation of higher amounts of drugs and also to alter the drug release profile. The process of drug release using these matrices occurs by mechanisms of swelling followed by diffusion after the contact with the receptor medium $[11,14,15]$. Nevertheless, this swell ability may limit the application of these materials as implants because the size changes can damage the soft tissues and cause inflammatory responses due to the expansion of the matrix [16].

Thereby, the objective of this work was to assess the swelling degree of the ureasil polyether hybrid materials during the contact with the biological environment and assess their biocompatibility in vivo. It is important to hightlight that it is a preliminar study to detect biocompatibility as stablished by the American Dental Association [17-19]. The obtention of favorable results may represent, in the future, a less expensive option of synthetic biomaterial capable of assisting in the process of bone regeneration. Also, these membranes could act as physical barriers and as drug carriers.

\section{Experimental}

\subsection{Preparation of ureasil-polyether hybrid materials}

The ureasil-polyether hybrid materials were synthesized by the well-known sol-gel process [12]. Synthesis was started from a functionalized polyether, based on polyethylene oxide $\left(\mathrm{NH}_{2}-\right.$ PEO- $\mathrm{NH}_{2}$ ) of molecular weight $1900 \mathrm{~g} \cdot \mathrm{mol}^{-1}$, or based on polypropylene oxide $\left(\mathrm{NH}_{2}-\mathrm{PPO}-\mathrm{NH}_{2}\right)$ of molecular weight $400 \mathrm{~g} \cdot \mathrm{mol}^{-1}$, dissolved in tetrahydrofuran $[11,13]$. To this solution was added a modified alkoxide, 3-(isocyanatopropyl)triethoxysilane (IsoTrEOS), in a polymer/alkoxide molar ratio of 1:2. The solution remained under reflux during $24 \mathrm{~h}$ at $80^{\circ}$ $\mathrm{C}$, to promote the formation of the hybrid precursor $(\mathrm{EtO})_{3} \mathrm{Si}$ $\left(\mathrm{CH}_{2}\right)_{3} \mathrm{NHC}(=\mathrm{O}) \mathrm{NHCHCH}_{3} \mathrm{CH}_{2}$-(polyether)- $\mathrm{CH}_{2} \mathrm{CH}_{3} \mathrm{CHNH}$ $(\mathrm{O}=) \mathrm{NHC}\left(\mathrm{CH}_{2}\right)_{3} \mathrm{Si}(\mathrm{OEt})_{3}$ [11]. Subsequently, the solvent was removed by heating under reduced pressure to form the hybrid precursor. Hereafter, the hybrid precursor was subjected to hydrolysis and condensation reactions, promoted by adding ethanol, water, and catalyst $\mathrm{HCl}$ solution (2M). During these reactions, the $\mathrm{OH}$ groups were progressively eliminated [16], leading to the formation of the ureasil-polyether hybrids materials (ureasil-PPO400 or ureasil-PEO1900).

\subsection{Swelling evaluation of the ureasil-polyether materials (small-angle x-ray scattering)}

To associate the swelling of the ureasil-polyether materials with injuries that could trigger an inflammatory response, the swelling behavior was monitored in vitro at nanoscale level. Temporal changes in nanoscopic structure of the samples imbebed in artificial saliva were assessed by small-angle $\mathrm{X}$-ray scattering (SAXS) measurements. Data collection were recorded at the synchrotron SAXS 1 beamline at LNLS (Campinas, Brazil). This beamline is equipped with a asymmetrically cut and bent $\mathrm{Si}$ (111) monochromator that produces an horizontally focused beam $(\lambda=0.1608 \mathrm{~nm})$. A vertical position-sensitive X-ray detector and a multichannel analyzer were used to record the SAXS intensity, $I(q)$, as a function of the modulus of the scattering vector $q=(4 \pi / \lambda)$ $\sin (\varepsilon / 2)$, with $\varepsilon$ being the scattering angle. The SAXS patterns of dried samples were recorded at $37^{\circ} \mathrm{C}$. The in situ swelling process monitoring was performed immersing discs of the samples in artificial saliva heated at $37^{\circ} \mathrm{C}$, with SAXS patterns being recorded every $30 \mathrm{~s}$.

\subsection{Animals model}

Sixty male Wistar rats (Rattus Norvegicus Albinus Holtzman) weighing between 250 and $300 \mathrm{~g}$ from the Biotherium of the Faculty of Dentistry of Araraquara (FOAr), UNESP, were assessed. The rats were kept in a quiet room with controlled temperature $\left(21 \pm 1^{\circ} \mathrm{C}\right)$ and humidity $(65-70 \%)$ and with a 
partially reversed day/night cycle, illuminated for $12 \mathrm{~h} /$ day. Animals had constant access to rat chow and received tap water ad libitum. All protocols described below were approved by the Ethical Committee on Animal Experimentation of the Faculty of Dentistry of Araraquara-UNESP, within the regulations established by the Brazilian College of Animal Experimentation (COBEA, Proc, CEEA n 23/2009).

\subsection{Wound induction}

The wound induction was conducted following the classical model previously described by Barbul et al. [20]. Briefly, the rats randomly divided into three groups $(\mathrm{n}=20$ each) were anesthetized by the administration of a mixture of ketamine ( $80 \mathrm{mg} / \mathrm{kg}$; Francotar, Virbac do Brasil Ltda, São Paulo, Brazil) and xylazine $(20 \mathrm{mg} / \mathrm{kg}$; Virbaxil, Virbac do Brasil). Afterward, a $15 \mathrm{~mm}$ dorsal skin incision was made under sterile conditions. Subcutaneous pockets were created and a collagen membrane (group I), ureasil-PPO400 (group II), and ureasilPEO1900 (group III) were implanted. The wounds were closed with running 3-0 silk sutures and five rats of each group were euthanized in four experimental periods (three, seven, 15, and 30 days) by an anesthetic overdose.

\subsection{Samples collections and histological examination}

Immediately after the euthanasia, the wounds were opened. The tissue samples were carefully removed, dissected and fixed in $10 \%$ formalin for $48 \mathrm{~h}$. After fixation, the specimens were dehydrated in ethanol, cleared in xylene, and embedded in paraffin. Five-micron-thick sections were prepared and mounted on glass slides, dewaxed, rehydrated, with distilled water, and stained with hematoxylin eosin $(\mathrm{H} \& \mathrm{E})$ and with Masson triple stain.

All slides were examined by a pathologist in relation to the inflammation process and granulation tissue (fibroblasts, capillaries, or collagen deposition), without knowledge of the previous treatment, under a microscope from $10 \times$ to $40 \times$ magnification.

\section{Results and discussion}

\subsection{Preparation of ureasil-polyether membranes}

The ureasil-polyether membranes were prepared by the sol-gel process (see section 2.1). This process allows the obtention of organic materials without decomposition and with controlled size, pores and surface area, at low temperature. However, this process can lead to rapid and abrupt contraction, generating an internal stress caused by the evaporation of the solvent, which may result in cracked materials. The visual aspect of ureasil-PPO membrane was shown in the graphical abstract, showingd homogeneus surface, without the presence of cracks. Previous studies [13-16,21] showed that these materials have high mechanical and thermal resistance, allow drug delivery, and are able to adhere to the biological substrate. These characteristics reveal that ureasil-polyether materials are promising candidates to enhance the success of guided bone regeneration.

\subsection{Swelling of the ureasil-polyether hybrids materials}

The nanostructural homogeneity and the swelling of the ureasil-polyether materials in the presence of water and phosphate buffer have been previously studied [11-14]. However, the presence of salts and other components of some biological fluids may change the hydration and solvation of these materials and, consequently, change the degree of swelling. Therefore, the ureasil-polyether materials were analyzed by SAXS measurements performed in the presence of artificial saliva, composite of $\mathrm{NaCl}, \mathrm{KCl}, \mathrm{CaCl}_{2} \cdot 2 \mathrm{H}_{2} \mathrm{O}$, citric acid, urea, $\mathrm{Na}_{2} \mathrm{~S} \cdot{ }_{9} \mathrm{H}_{2} \mathrm{O}, \mathrm{NaH}_{2} \mathrm{PO}_{4 \cdot \mathrm{H} 2} \mathrm{O},\left(\mathrm{NH}_{4}\right)_{2} \mathrm{SO}_{4}$, and $\mathrm{NaHCO}_{3}(\mathrm{pH}$ 7.1). Artificial saliva was chosen as sweelling medium due to its similarity with the oral environment. The ureasil-polyether materials are formed by an organic polymeric chain and by an inorganic phase containing Si-O-Si crosslinking nodes. Figure 1 shows the chemical strucuture of the ureasil-polyether molecule and a representation of spatial organization of the crosslinking nodes.

The SAXS technique is used to characterize these hybrid materials, as they present different electronic density between crosslinking nodes and the organic chains. The correlation distance between two crosslinking nodes can be calculated by SAXS using the equation: $\xi=2 \pi / q_{\max }$ ( $q_{\max }$ is the value of the scattering vector $q$ corresponding to the position of the maximum correlation peak; see Figure 1).

Figures 2 and 3 show the temporal evolution of SAXS curves for ureasil-PPO400 membrane, and for the ureasil PEO-1900 membrane, respectively. In both figures, the curve at time 0 correspond to the dried sample before their contact with artificial saliva.

The presence of a single large peak can be observed in the Figures 2 and 3. It is characteristic of strong spatial correlation between the crosslinking nodes [11]. Besides, in the Figure 2 the maximum position of the correlation peak is unaffected during the time, indicating that the correlation distance

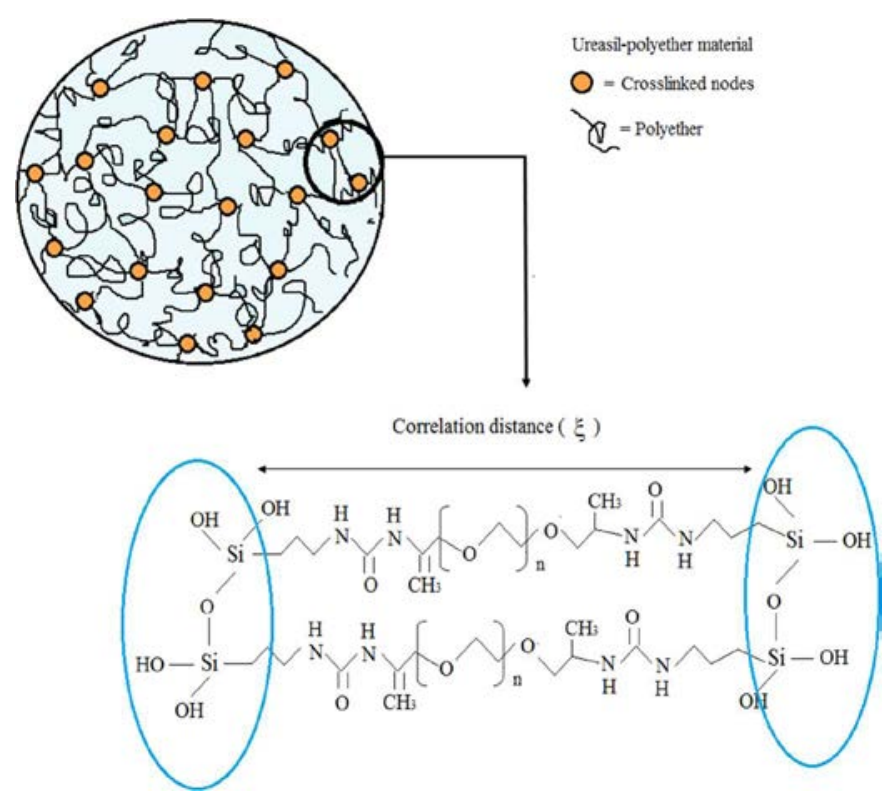

Figure 1. Chemical strucuture of the ureasil-polyether molecule and the representation of spatial organization of the crosslinking nodes. 


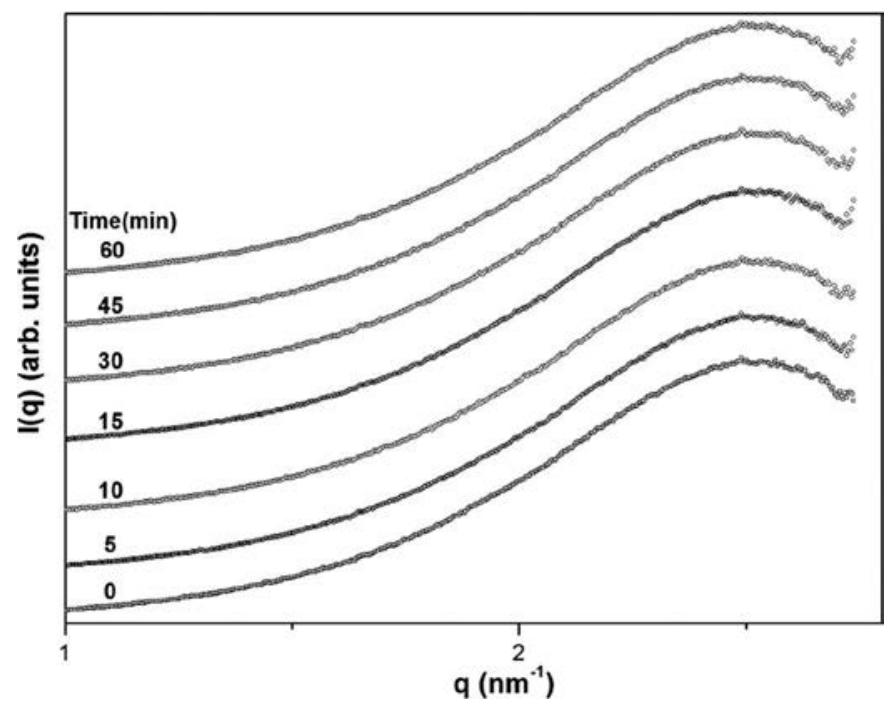

Figure 2. Time evolution of SAXS curves of ureasil-PPO400 imbebed in artificial saliva.

between crosslinking nodes $(\xi)$ remains equal to $2.5 \mathrm{~nm}$. This behavior is expected because ureasil-PPO400 has hydrophobic character, which hinders the entrance of artificial saliva on its structure. This behavior is the same observed in the presence of water or phosphate buffer [11-14], indicating that the salts present in the artificial saliva does not alter their swelling profile.

Figure 3 shows a significant shift in the maximum position of the correlation peak to low $q$ values as function of time. After $60 \mathrm{~min}$ in contact with artificial saliva, the correlation distance shifts from 4.6 to $6.3 \mathrm{~nm}$, revealing a significant increase in the distance between the crosslinking nodes.

In this case, their hydrophilic character is responsible for their higher affinity with the media and, therefore, higher capacity of swelling. This behavior is also similar to the observed in the presence of water or phosphate buffer [1114]. As already observed for PPO400, artificial saliva does

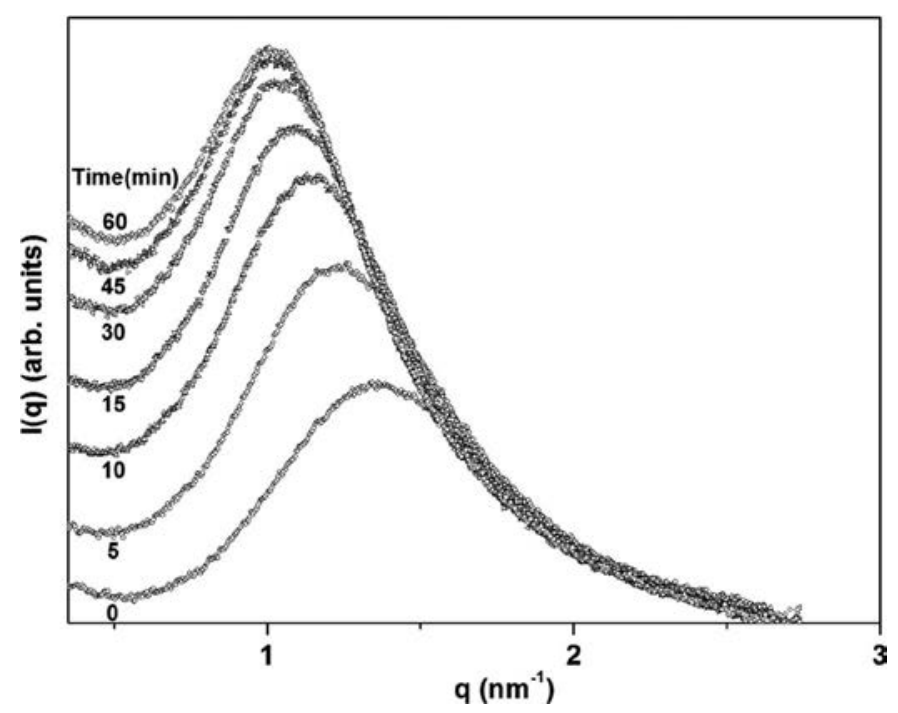

Figure 3. Time evolution of SAXS curves of ureasil-PEO1900 imbebed in artificial saliva.

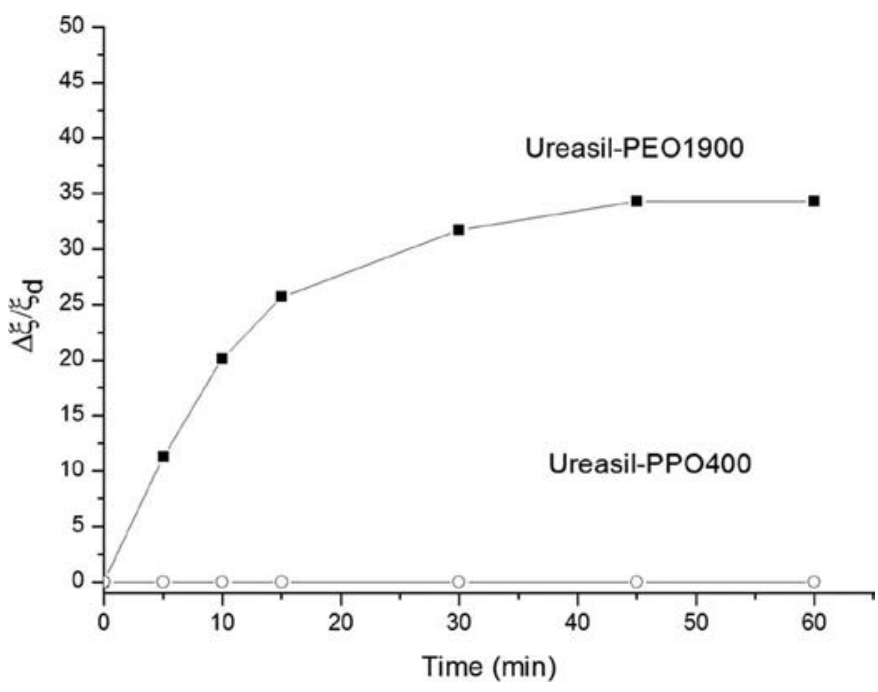

Figure 4. Evolution of $\Delta \xi / \xi_{\mathrm{d}}$ of ureasil-PEO1900 as function of time immersion in artificial saliva.

not modified the swelling profile of ureasil-polyether materials.

The hydration of the cross-linked network is an important structural parameter, which is relative to the elongation ratio $\left(\xi_{\mathrm{s}}-\xi_{\mathrm{d}}\right) / \xi_{\mathrm{d}}$. Considering the SAXS results, relative elongation ratio $\left(\xi_{\mathrm{s}}-\xi_{\mathrm{d}}\right) / \xi_{\mathrm{d}}$ was calculated from the average distance between crosslinking nodes measured in the dry state $\left(\xi_{\mathrm{d}}\right)$ and after different swelling periods $\left(\xi_{s}\right)$. Figure 4 shows the $\Delta \xi / \xi_{\mathrm{d}}$ evolution of the ureasil-PEO1900 immersed in artificial saliva as function of time.

It was observed the occurrence of a swelling process between two crosslinking nodes (aproximatelly 33\%) to ureasil-PEO1900. This phenomenon occurs due to the adsorption of artificial saliva through the matrix, which is hydrophylic. The swelling equilibrium was attained after $45 \mathrm{~min}$. The same experiments were performed with ureasil-PPO400, however, there was no sweeling (Figure 4). These swelling behaviors suggest that ureasil-PEO1900 can damage soft tissues and cause inflammatory responses due to the ability to swollen in presence of artifical saliva.

\subsection{Microscopic aspects}

The microscopic assessment of the H\&E and Masson triplestained sections at magnifications of $10 \times$ or $40 \times$ of all groups are shown on Figure 5.

According to the histological analysis, all materials assessed promoted inflammation. Cellular infiltrate and classical granulation tissue formation were correlated with the experimental periods.

The collagen material (BioGide) represented by group I showed inflammation at period of three and seven days. Around the collagen membrane, the infiltration of polymorphonuclear cells was maximal on the third day folloewd by a decline, whereas lymphocyte/macrophage infiltration increased progressively up to seventh day. In the 15th and 30th days, classical organization of granulation tissue was observed in the subsequent periods (i.e., fibroblasts and 


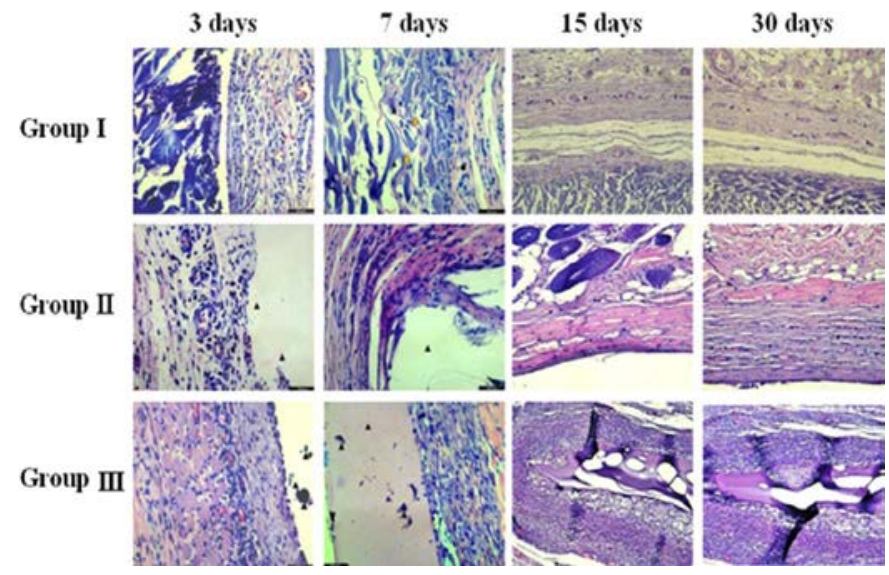

Figure 5. The microscopic assessment of the $\mathrm{H} \& \mathrm{E}$ and masson triple-stained sections at magnifications of $10 \times$ or $40 \times$ to collagen membrane (group I), ureasil-PPO400 membrane (group II) and ureasil-PEO1900 (group III).

collagen deposition increased over time throughout the experimental periods). These absorbable membranes are currently used due to its biocompatibility, and mainly because they do not require a second surgical procedure for its removal, being absorbed or incorporated into the scar tissue [22]. Collagen membranes are absorbed by enzymatic activity (collagenase) from macrophages and polymorphonuclear leukocytes.

The clinical use of collagen membranes for bone regeneration has shown promising results in the preservation of peri-implant marginal bone. The collagen membranes have a porous structure, occlusive to cells but allow the passage of fluid and plasma proteins [23].

The ureasil-PPO400 material (GII) promoted inflammation at third and seventh days. At 15 days of implantation, large amounts of vascular figures and intense population of inflammatory cells were detected and consequently there was fibroblasts proliferation but decrease of collagen fibers due to the presence of membranes. There were significant differences in the histophatological patterns of the inflammatory cells influx and organization of granulation tissue around the sample. Within the dermis was noted well-defined space occupied by eosinophilic amorphous material. Involving this space, there are fibrous capsule formed by collagen fibers arranged horizontally. Also, fusiform cells, leucocytes and new blood vessels formed were verified. At 30th day, the material did not suffer absorption and the epidermis showed aspects of normality. The normality of epidermis aspect after 30 days indicates that this membrane is a good candidate to be used as biological membrane for implantable sytem.

The ureasil-PEO1900 material (GIII) presented constant inflammation levels in all the analysed periods. In the slides, it can be seen a significant presence of giant cells and exacerbation of the influx of inflammatory process mainly up to seven days. Within the dermis was well bounded space occupied by eosinophilic amorphous material similar to the group II. Within the dermis there is a well-defined space filled with basophilic and amorphous material. Involving this space a capsule formed by collagen fibers arranged in a disordered manner interspersed with intense inflammatory cell infiltrate composed primarily of mononuclear leukocytes (macrophages and lymphocytes). New blood vessels of different sizes were also observed, and they where rich of red blood cells (vascular stasis).

Inflammatory levels were initially equal for all materials tested in the periods of 3-7 days. The body initially recognizes the materials as foreign bodies, and triggers an inflammatory proccess. The reaction of the foreign body can present an impact on the biocompatibility of the biomaterial causing tissue damage. The interaction of immune system with the cells and the biomaterial is crucial to understand the biocompatibility of a material, even the function of this material [23]. After implantation of a biomaterial, the reaction of the host includes an interaction between injury and material and is formed a provisional matrix. In this point occur an acute inflammation that may or not be replaced by a chronic inflammation. Moreover, the foreign body reaction develops a fibrosis, which leads to the formation of a fibrous capsule.

This matrix is initially called as thrombus or blood clot, which is localized in the interface tissue/material. The damage of vascularized conjunctive tissue, not only initiates the inflammatory response but also leads to thrombus formation involving activation of the intrinsic and extrinsic coagulation system, fibrinolytic system and the system of generation of kinin and platelets. These cascades of protein may be intimately involved in the dynamic phenomenon of adsorption of protein known as the Vroman effect [24]. The formation of the provisional matrix is described as the deposition of proteins on the surface of the biomaterial. This matrix provides biochemical and structural components for the process of healing and foreign body reactions. The provisional matrix can be seen as a system of release of natural derivatives, wherein the bioactive agents are released to control subsequent stages of healing [23-25].

The ureasil-POE1900 membrane (group III) revealed an acute inflammation in the all periods evaluated, with lot of cells that characterize this response as giant cells, neutrophils and leukocytes, the acute inflammation. After, the chronic inflammation is identified by the presence of mononuclear cells (monocytes and lymphocytes) in the implant site. Chronic inflammation is less uniform than acute inflammation. These results may be related to the high degree of swelling of materials ureasil-PEO1900 (item 3.1, swelling of the ureasil-polyether hybrids materials) because the expansion of the material after contact with the environmental media can damage the internal tissues accentuating the immune response. Thus, comparing groups II and III is undoublty that the ureasil-PPO400 membrane offered promising results because after 15 days the epidermis shown normal aspect, being cessed the inflammation.

The advantage in relation to group $\mathrm{I}$ is the ability to promote drug vehiculation.

\section{Conclusion}

The swollen characteristics associated to in vivo biocompatibility experiments revealed that ureasil-PPO400 membrane evaluated in this study can be in the future a new option of synthetic biomaterial able to assist in the processes of bone regeneration, because after 15 days of grafting no signals of 
inflammation were verified, being the tissue aspect similar to the treated with biocompatible colagen membrane. Adittionally these membranes can control the delivery behavior of different drugs as shown in previous works and consequently be used not only as a barrier membrane but also to control the delivery of antiinflamatory drugs or biological active molecules able to improve the bone growth.

\section{Funding}

FAPESP, LNLS, CNPq, and PADC/FCF-UNESP for the financial support.

\section{References}

[1] Geiger, M.; Li, R. H.; Friess, W. Adv. Drug Deliv. Rev. 2003, 55, 1613-1629.

[2] Moghadam, H. G.; Urist, M. R.; Sandor, G. K.; Clokie, M. J. Carniofac. Surg. 2001, 12, 119-127.

[3] Takeda, S.; Karsenty, G. J. Bone Miner. Metab. 2001, 19, 195-198.

[4] Carvalho, P. S.; Marianom, R. C.; Okamoto, T. Braz. Dent. J. 1997, 8, 3-8.

[5] Lane, J. M.; Yasko, A. W.; Tmin, E.; Cole, B. J.; Waller, S.; Browne, M.; Terek, T.; Gross, J. Clin. Orthop. Relat. Res. 1999, 361, 216-227.

[6] Misch, C. E. Dent. Today 2002, 21, 1-62.

[7] Summers, B. N.; Eisentein, S. M. J. Bone Joint Surg. Br. 1989, 71, 677-680.

[8] Brown, M. D.; Mailinin, T. I.; David, P. B. Clin. Orthop. 1996, 119, 231-236.

[9] Hardesty, R. A.; Marsh, J. L. Plast. Reconstruct. Surg. 1990, 85, 5-14.

[10] Park, J. S.; Choi, S. H.; Moon, I. S.; Cho, K. S.; Chai, J. K.; Kim, C. K. J. Clin. Periodontol. 2003, 30, 443-453.
[11] Santilli, C. V.; Chiavacci, L. A.; Lopes, L.; Pulcinelli, S. H.; Oliveira, A. G. Chem. Mater. 2009, 21, 463-467.

[12] Gonçalves, M. C.; De Zea Bermudez, V.; Sá Ferreira, R. A.; Carlos, L. D.; Ostrovskii, D.; Rocha, J. Chem. Mater. 2004, 16, 2530-2543.

[13] Dahmouche, K.; Souza, P. H.; Bonagamba, T. J.; Paneppucci, H.; Judeinstein, P.; Pulcinelli, S. H.; Santilli, C. V. J. Sol-Gel Sci. Technol. 1998, 13, 909-913.

[14] Oshiro JR, J. A.; Shiota, L. M.; Chiavacci, L. A. Matéria 2014, 19, 24-32.

[15] Molina, E. F.; Pulcinelli, S. H.; Santilli, C. V.; Blanchandin, B.; Briois, B. J. Phys. Chem. B 2010, 114, 3461-3466.

[16] Lopes, L.; Molina, E. F.; Chiavacci, L. A.; Brios, V.; Pulcinelli, S. H. RSC Adv. 2012, 2, 5629-5636.

[17] American Dental Association. Council on dental and materials and devices of the American Dental Association. J. Am. Dent. Assoc. 1972, 84, 375-395.

[18] American National Standards Institute/American Dental Association. Document no. 41 for Recommended Standard Practices 430 for Biological Evaluation of Dental Materials. Council on Dental Materials and Devices. J. Am. Dent. Assoc. 1979, 99, 697-698.

[19] Stanley, H. R. Int. Dent. J. 1992, 42, 37-46.

[20] Barbul, A; Fishel, R. S.; Shimazu, S; Wasserkrug, H. L; Yoshimura, N. N; Tao, R. C; Efron, G. J. Surg. Res. 1985, 38, 328-334.

[21] Oshiro-JR, J. A.; Carvalho, F. C.; Soares, C. P.; Chorilli, M.; Chiavacci, L. A. Int. J. Polym. Sci. 2015, 2015, 1-7.

[22] Dempster, D. W.; Parisien, M.; Silverberg, S. J.; Liang, X. G.; Schnitzer, M.; Shen, V. J Clin. Endocrinol. Metabol. 1999, 84, 1562-1566.

[23] Takakis, D. N.; Promsudthi, A.; Wikesjo, U. M. Periodont. 2000, 19, 59-73.

[24] Zitzmann, N. U.; Scharer, P.; Marinello, C. P. Int. J. Oral Maxillof. Implant. 2001, 16, 355-366.

[25] Anderson, J. M.; Rodriguez, A.; Chand, D. T. Semin. Immunol. 2008, $20,86-100$

[26] Horbett, T. Biomaterials Science: An Introduction to Biomaterials In Medicine; San Diego, CA: Elsevier Academic Press, 2004. 